\title{
Las pensiones por muerte no profesional, su discrepancia con la finalidad de la seguridad social y la protección de los medios de subsistencia.
}

Pensions for non-professional death, their disagreement with the purpose of social security and the protection of means of subsistence.

Tania. Arteaga-Nivio ${ }^{a}$

\begin{abstract}
:
The purpose of Social Security in Mexico in addition to guaranteeing the right to health, medical care, social services, or the right to a pension, is the protection of the means of subsistence, which is violated when the Law of Insurance itself Social establishes a limit to pensions in case of death in the Disability and Life insurance for pensioners due to widowhood, orphanage and ancestry, when the unprofessional death of the pensioner due to disability or the insured person occurs and, together with the low amounts for concept of family allowances and assistance, pensions in general, seem not to contribute to a decent subsistence in Mexican families.
\end{abstract}

Keywords:

Pensions, disability, Livelihoods, progressiveness

\section{Resumen:}

La finalidad de la Seguridad Social en México además de garantizar el derecho a la salud, la asistencia médica, servicios sociales, o el derecho a una pensión, es la protección de los medios de subsistencia, misma que se vulnera cuando la propia Ley del Seguro Social establece un límite a las pensiones en caso de muerte en el seguro de Invalidez y Vida para los pensionados por viudez, orfandad y ascendencia cuando se presenta la muerte no profesional del pensionado por invalidez o del asegurado y que aunado a las bajas cuantías por concepto de asignaciones familiares y ayudas asistenciales, las pensiones en general, parecen no contribuir a una digna subsistencia en las familias mexicanas.

Palabras Clave:

Pensión, invalidez Medios de subsistencia, progresividad

\section{Introducción}

La seguridad social es un derecho de todo ser humano contemplado en la Constitución Política de los Estados Unidos Mexicanos (CPEUM) que brinda protección y bienestar a los trabajadores y a sus familias; otorgada a través del Instituto Mexicano del Seguro Social (IMSS) y regulado por la Ley del Seguro Social (LSS). Normas que contemplan principios, objetivos o propósitos, respetando constantemente los derechos humanos. Específicamente en la Ley del seguro social se encuentra el Seguro de Invalidez y Vida, cuyos riesgos protegidos son: La Invalidez, es decir, cuando el trabajador de manera temporal o definitiva se ve imposibilitado para procurarse económicamente al disminuir o extinguirse su capacidad laboral y, la muerte, esto es, el derecho de los beneficiarios a percibir una pensión al fallecimiento del asegurado. Seguro destinado a proteger los medios de subsistencia del trabajador y su familia, es decir, los medios que permitan a las personas cubrir sus necesidades vitales; garantizar el derecho a la salud a través de la asistencia médica, entre otros servicios y prestaciones, siempre que dicha invalidez o muerte del asegurado se deba a riesgos no profesionales (IMSS, 2014).

Enfocándome en la idea de que el Estado debe garantizar el otorgamiento de una pensión digna y la protección de los medios de subsistencia. "La dignidad es el fundamento de los derechos humanos, que buscan la plena realización de los seres humanos a través de la conquista de condiciones de vida que les permita mejorar su entorno y hacerse partícipes de su propio desarrollo" (Suarez, 2009 
p.61), de tal manera que la ley al establecer un límite a las pensiones por muerte, precariza y agrava la situación económica, social y cultural para los beneficiarios de un pensionado o asegurado en caso de sufrir una muerte no profesional, puesto que, la pensión en el seguro de invalidez y vida resulta en la mayoría de los casos insuficiente e injusta, ante la contribución económica que el trabajador en vida realizó para financiar los seguros otorgados por el Régimen obligatorio incorporación forzosa al IMSS, ya sea mediante el pago de impuestos o a través del pago de cuotas al Instituto, contribución basada en los principios de subsidiariedad y solidaridad.

De manera global se hablará de la normatividad nacional en la Constitución Política de los Estados Unidos Mexicanos; la Ley del Seguro Social, asimismo de normas Internacionales como la Declaración Universal de los Derechos Humanos, el Pacto Internacional de los Derechos económicos, sociales y culturales y los principios de solidaridad y subsidiariedad; el análisis del seguro de Invalidez y vida con el principio de progresividad previsto en nuestra Carta Magna y su relación con el limite a las pensiones por muerte no profesional.

\section{Normatividad}

Para empezar la Constitución Política de los Estados Unidos Mexicanos en su artículo 123 apartado A, fracción XXIX, establece que:

Es de utilidad pública la Ley del Seguro Social, y ella comprenderá seguros de invalidez, de vejez, de vida, de cesación involuntaria del trabajo, de enfermedades y accidentes, de servicios de guardería y cualquier otro encaminado a la protección y bienestar de los trabajadores, campesinos, no asalariados y otros sectores sociales y sus familiares. ( $p$. 137)

En segundo lugar, de lo establecido en el artículo 2 de la Ley del Seguro Social, dice:

La seguridad social tiene por finalidad, la idea de que el Estado debe garantizar la salud, la asistencia médica, la protección de los medios de subsistencia y los servicios sociales para el bienestar individual y colectivo, así como el otorgamiento de una pensión. (p.1)

La seguridad social se conforma de varias garantías o principios, dos de ellos básicos para poder entender la idea del derecho a una pensión en el seguro de invalidez y vida, de manera digna y sin límites. El primero de ellos basado en el principio de subsidiariedad que consiste en distribuir las responsabilidades o cargas económicas entre los sujetos participantes, como lo son: Los asegurados al régimen obligatorio, los empleadores y el estado que servirán para contribuir al financiamiento de los seguros o contingencias previstas en la ley del seguro social, a través, de las cuotas tripartitas. $Y$ el segundo, el principio de solidaridad en donde de manera colectiva y solidaria se comparten tanto los riesgos como los beneficios, es decir, mientras que unos padezcan de una enfermedad y por consiguiente de una incapacidad o pensión, otros de manera solidaria contribuyen junto al estado para garantizar las contingencias que se presenten mediante el otorgamiento de prestaciones en dinero o en especie, sin importar el número de integrantes de la familia o beneficiarios de cada asegurado (García, 2014).

En el ámbito Internacional la Declaración Universal de los Derechos Humanos es un documento que contiene 30 artículos que establecen derechos humanos fundamentales. Siendo proclamada por la Asamblea General de las Naciones Unidas en París, el 10 de diciembre de 1948 en su Resolución 217 A (III) específicamente en su artículo 22 establece:

Toda persona, como miembro de la sociedad, tiene derecho a la seguridad social, y a obtener, mediante el esfuerzo nacional y la cooperación internacional, habida cuenta de la organización y los recursos de cada Estado, la satisfacción de los derechos económicos, sociales y culturales, indispensables a su dignidad y al libre desarrollo de su personalidad.

A continuación, en su Artículo 23 numeral 3 La Declaración de los Derechos humanos Comenta que: Toda persona que trabaja tiene derecho a una remuneración equitativa y satisfactoria, que le asegure, así como a su familia, una existencia conforme a la dignidad humana y que será completada, en caso necesario por cualesquiera otros medios de protección social.

Y en su artículo 25 reza lo siguiente:

Toda persona tiene derecho a un nivel de vida adecuado que le asegure, así como a su familia, la salud y el bienestar, y en especial la alimentación, el vestido, la vivienda, la asistencia médica y los servicios sociales necesarios; tiene asimismo derecho a los seguros en caso de desempleo, enfermedad, invalidez, viudez, vejez u otros casos de pérdida de 


\section{sus medios de subsistencia por circunstancias independientes de su voluntad.}

En resumen, estos preceptos exteriorizan en primer lugar el derecho de toda persona a la seguridad social, tendiente a satisfacer los derechos económicos, sociales y culturales, (DESC) necesarios para la dignidad del hombre, lo que se traduce al bienestar del trabajador y su familia para mejorar su salud y el nivel económico de vida, mediante una remuneración que garantice su subsistencia. Obligación del Estado que incluso puede llevarse a cabo por otros medios de protección social, como son los programas sociales.

Siguiendo ese mismo orden de ideas, el Pacto Internacional de los Derechos económicos, sociales y culturales. (PIDESC), que forma parte de la Carta Internacional de Derechos Humanos, habrán de satisfacerse dependiendo de la buena organización y recursos del Estado mexicano. Los Derechos Económicos, Sociales y Culturales (DESC), reconocidos por la Organización de Naciones Unidas (ONU) expresan los derechos de todo ser humano, necesarios para una vida digna, social y económica, que versan en derechos como: El trabajo, la vivienda, la seguridad social, la cultura, educación, alimentación, vestido, el derecho a gozar de agua, entre otros, debiendo implicar un bienestar social, que no solo consiste en proporcionar por el Estado al individuo el derecho a la seguridad social y el acceso a una pensión, sino que debe garantizarse la justica económica (Red DESC, s.f.). Lo anterior debe estar ligado en específico con en el principio de Progresividad previsto en el artículo 1․de nuestra Carta Magna y una de las principales características de los derechos humanos, es decir, para la aplicación del principio de progresividad éste debe entenderse como la ampliación de los derechos humanos a favor de los trabajadores, siendo una obligación del estado promover y respetar dicho principio. Así pues, la obligación progresiva del Estado respecto de Ios DESC dependerá de sus recursos económicos para que pueda garantizarlos, deberá otorgarlos de manera gradual y hacer uso eficaz de sus recursos que de manera progresiva tiendan a mejorar las condiciones de vida más nunca de forma regresiva, es decir, implementando medidas que empeoren la situación de dichos derechos (Valencia, 2009).

Sin embargo, para que esto se cumpla debe existir la obligatoriedad de contribuir como asegurado al pago de las cuotas tripartitas al seguro social, fundamentado en los ya mencionados principios de Solidaridad y Subsidiariedad. Entonces, cuando la realidad no suele concordar con las normas, principios, ni con la finalidad de la seguridad social de garantizar la protección de los medios de subsistencia, sirve pues de base para justificar que el limite a las pensiones para los beneficiarios en el seguro de Invalidez y Vida es injusto y vulneran dichas medidas. Pongámoslo más entendible, a pesar de que la Ley del Seguro Social establece una cuantía del 90\% para la viuda; 20 o 30\% para los hijos, dependiendo si son huérfanos de padre o madre o de ambos y un $20 \%$ para los ascendientes, finalmente termina limitando la suma de pensiones a la cuantía básica del 35\% del Salario diario promedio de las últimas 500 semanas cotizadas, o sea, los beneficiarios reciben en suma nuevamente el monto de la pensión que percibía el pensionado por Invalidez en vida o bien a la que le hubiere correspondido por ese concepto, como límite, pues el total de las pensiones por viudez, orfandad o ascendencia no deberán exceder de esa cuantía básica del 35\%

\section{Las afores en México}

Precisamente derivado de las contribuciones obligatorias de los asegurados y de la implementación a partir del $1^{\circ}$ de julio de 1997 del sistema de cuentas individuales, surgen las AFORES, Administradoras de Fondo de Ahorro para el retiro. Estas instituciones financieras reportan ganancias millonarias por el simple cobro de la cuota que descuentan al trabajador por la administración de dicho ahorro y aún más por la inversión que hacen de los recursos acumulados en las cuentas individuales de cada uno de los trabajadores asegurados por las llamadas Sociedades de Inversión Especializadas en Fondos de Ahorro para el Retiro (SIEFORES) incluso en la Bolsa de Valores. (Amezcua, 2002). Al respecto la revista Forbes, México establecía que a partir de la creación de las afores en 1997 y cuando el estado delego el sistema de pensiones a los bancos, los rendimientos o ganancias de los trabajadores solo alcanzaban el $15.8 \%$, lo que representa el inferior a un punto porcentual en promedio anual, lo que hace que las administradoras de fondo de ahorro para el retiro se enriquezcan a costa de las cuentas individuales de los trabajadores, situación en la que es participé también la propia Comisión Nacional de Sistema de Ahorro para el Retiro, pues es ésta quien determina a su vez la comisión a cobrar por parte de la afore. (Ameth, 2015). Aclaremos entonces, en un informe de la Comisión Nacional del Sistema de Ahorro para el Retiro (CONSAR, 2019) se dio a conocer que, al cierre de mayo de 2019 , se han abierto 63.9 millones de cuentas individuales, por lo que el Sistema de Ahorro para el Retiro acumula 3.61 billones de pesos de ahorro pensionario, entre los que cotizan en el IMSS e ISSSTE cifra que representan el $15.1 \%$ del Producto Interno Bruto del país, ahorro que representa un significativo sostén en el patrimonio de los mexicanos. Lo que peor, las afores en México en comparación con Estados Unidos, cobran el doble de comisión, esto es, la comisión a pagar por parte de los mexicanos a la afore por la administración de su cuenta 
es de $0.98 \%$ en contraste con el $0.45 \%$ que se cobra en Estados Unidos, siendo las comisiones más altas a diferencia de otros países (Ver figura 1), mientras que los ingresos por comisiones de las afores alcanzan un máximo de 32 mil millones de pesos (Sin embargo, 2019). ¿Por qué, entonces las pensiones no son suficientes para obtener mejores condiciones de vida?

Es quizás por este motivo, que la actual administración pretende disminuir la comisiones que cobran las afores de $0.98 \%$ actual a $0.70 \%$ para 2024 como uno de sus compromisos con los mexicanos (SHCP-CONSAR, 2019). De manera que en mi opinión no hay motivo para limitar el pago de las pensiones en el ramo de invalidez y vida siendo válida la exigencia de pensiones justas para quienes han contribuido al crecimiento económico del país $y$ al enriquecimiento de estas entidades financieras. Por ejemplo y aunado a todo lo anterior, de datos estadísticos de la CONSAR, (2019) estableció que: "Se han destinados 1,216.052 millones de pesos del ahorro pensionario de los mexicanos al desarrollo de empresas mexicanas de distintos tamaños pertenecientes a distintos sectores de la actividad económica, ahorro que ha propiciado un círculo virtuoso para el desarrollo" (párr. 7).

Otro aspecto que se suma a las malas condiciones de salud y económicas de los trabajadores, es la precariedad laboral que afecta a cierta población carente de contrato escrito respecto a gozar de prestaciones y beneficios sociales (Garcia.2013) que, aunque por ley, la no existencia de un contrato escrito no exime al trabajador de derechos y prestaciones laborales ni de seguridad social. Sin embargo, el escenario en México y el desconocimiento aun de dichos derechos traen como consecuencia que al presentarse el riesgo de trabajo o un riesgo no profesional que deriven en una incapacidad, los trabajadores no suelen reclamar y con ello acceder al pago de salario, indemnización o pensión según sea el caso y, lo que comúnmente suele pasar es la mera suspensión de la relación laboral sin goce de sueldo o bien una causa de terminación en caso de tratarse de una incapacidad permanente, ya que el trabajador solo deja de asistir al empleo. De un estudio realizado en 2013, García establecía lo siguiente:

La precariedad de los trabajadores
mexicanos a inicios del año dos mil el
$55 \%$ de ellos contaba con seguridad
social pero solo el $54 \%$ tenía contratos
escritos. Condiciones que han
permanecido, e incluso se han
deteriorado durante lo que va del siglo
XXI (p.165)

De acuerdo con el Instituto Nacional de Estadística y Geografía la tasa de desocupación (TD) fue de 3.5\% de la Población Económicamente Activa (PEA) cuya última actualización fue el 26 de junio de 2019 y que, en comparación con igual mes del año 2018, la (TD) aumentó de $(3.5 \%$ vs $3.2 \%)$. Por otra parte, el número de trabajadores asegurados al IMSS en mayo de 2019 fue de 20,382,910 mientras que en mayo de 2018 fue de 19,908,072 (INEGI, 2019).

figura 1 Ingreso por comisiones como porcentaje de saldo 2018.

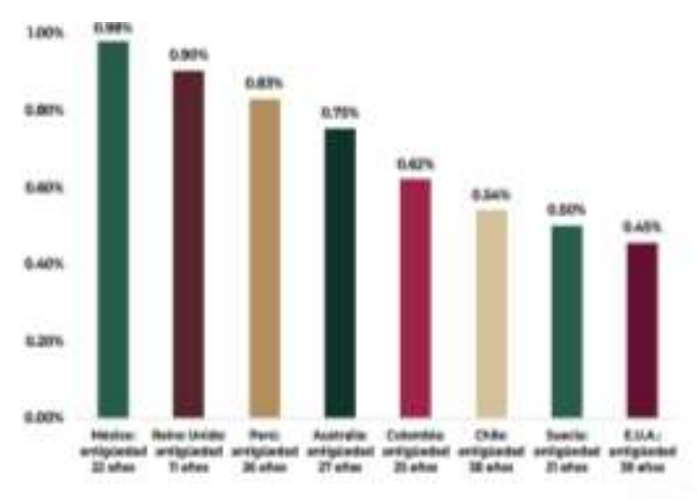

Foto: México reporta las comisiones más altas (SHCP- CONSAR, 2019).

\section{El seguro de Invalidez y Vida}

Conviene subrayar que los sistemas de seguridad social en otros países latinoamericanos buscan también proteger a sus ciudadanos de contingencias que afecten su salud, su capacidad económica y demás condiciones de vida. Siendo el objetivo de la seguridad social conseguir con la pensión para los sobrevivientes ante la muerte de su familiar asegurado o pensionado; la de evitar que la situación económica de dicha familia se empeore (Castillo, 2011).

En México, existe invalidez de acuerdo a la Ley del seguro social en su artículo 119 Cuando:

El asegurado se halle imposibilitado para procurarse, mediante un trabajo igual, a percibir una remuneración superior al $50 \%$ de su remuneración habitual percibida durante el último año de trabajo y siempre que esa imposibilidad sea derivada de un accidente o enfermedad no profesional. (p.37)

En otras palabras, la invalidez es derivada de un accidente o enfermedad no generado con motivo o en ejercicio del trabajo con excepción del denominado accidente en trayecto el que se ocasiona de manera directa de la casa del trabajador a la empresa y viceversa; riesgo no profesional que trae como consecuencia una disminución en la capacidad laboral que le impida al 
asegurado ahora pensionado desempeñar su trabajo y percibir más del $50 \%$ de lo que ganaba o percibía anterior a su invalidez. Posterior a ello, la declaración de invalidez que deberá ser realizada por médicos especialistas del propio Instituto Mexicano del Seguro Social y, dependiendo del grado de incapacidad se otorgará una pensión temporal o bien una pensión definitiva siempre y cuando el asegurado reúna las semanas cotizadas requeridas para el goce de la pensión, sí el grado de incapacidad es menor a $75 \%$ se requerirán 250 semanas y si fuese mayor a $75 \%$ el requisito serán 150 semanas cotizadas. Lo anterior si se encuentra bajo el amparo del régimen de la ley del seguro social de 1997. Si por el contrario se halla bajo el amparo del Régimen de la Ley del Seguro Social de1973 por haber cotizado antes del 1 de julio de 1997, deberá tener registradas ante el IMSS, como mínimo, 150 semanas de cotización. En ambos casos a la Pensión de invalidez se le sumaran otras prestaciones, entre ellas, las ayudas asistenciales, asignaciones familiares y el pago anual de 30 días de la pensión por concepto de aguinaldo.

De los artículos 122 y 127 de la Ley del Seguro Social de 1997 se resume que en casos de la pensión definitiva y en caso de fallecimiento del asegurado, la pensión y el seguro de sobrevivencia se contratarán por el asegurado en el primer caso y por los beneficiarios en el segundo, con la institución de seguros que se elija. Para la contratación de los seguros de renta vitalicia y de sobrevivencia, el Instituto calculará el monto constitutivo necesario para su contratación que se deberá integrar a la aseguradora elegida, el cual deberá ser suficiente para cubrir la pensión, las ayudas asistenciales y demás prestaciones. Para ello el IMSS otorgará una suma asegurada que, adicionada a los recursos acumulados en la cuenta individual del trabajador, deberá ser suficiente para integrar el monto constitutivo con cargo al cual se pagará la pensión por la institución de seguros. Dicho de otra manera, el asegurado deberá tener suficiente ahorro acumulado en su cuenta individual pues de este dependerá el monto de la pensión. Aclaremos más a fondo lo anterior, ¿Qué es la pensión definitiva? Y ¿porque hablamos de la aplicación de la ley del seguro social, de 1973 y 1997 ? La pensión definitiva es aquella que derivada de una invalidez y de un dictamen del IMSS se estima de naturaleza permanente. Con la reforma al programa del IMSS en 1995 que entró en vigor hasta el 1 de julio de 1997 se sustituye un esquema de reparto administrado por el IMSS por otro de capitalización basado en cuentas individuales por instituciones primordialmente privadas denominadas afores, sin embargo, esta modificación se encuentra muy lejos de que un trabajador adquiera un bienestar al momento de sufrir una invalidez o los beneficiarios tras la muerte del trabajador asegurado, sino todo lo contrario, con el cambio de sistema de pensiones a cuentas individuales la afore le cobrará por la administración de sus fondos de ahorro una comisión pero sin incrementar de manera significativa los rendimientos que generan la inversión de esos fondos (Ruiz, Barboa y Cuadras 2016).

La diferencia estriba en que, si la pensión es conferida con la ley de 1973 será con cargo al gobierno federal, es decir, derivadas de las contribuciones de los contribuyentes impuestos, pero al representarle un gasto significativo para el gobierno se optó por el régimen de cuentas individuales (IMSS, 2013), Esto es, la cuenta en la que se depositan las cuotas tripartitas trabajador, patrón y estado, que a su vez, se integran por 3 subcuentas: Retiro cuya aportación es de 1.125 , patrón $4.15 \%$ y gobierno 0.25 del salario base de cotización (SBC) reportado ante el IMSS; Aportaciones voluntarias y Vivienda. Además de la cuota social equivalente al $5.5 \%$ del Salario Mínimo. Y por lo que hace al seguro de Invalidez y Vida la aportación patronal es de $1.75 \%$ del SBC, para el trabajador de $0.625 \%$ y la contribución del estado es de $7.143 \%$ del total de la cuota patronal (Ley del Seguro social, 1995).

Lo que implica que las pensiones otorgadas por la ley 97 están basadas en rentas vitalicias (ver figura 2) contrato celebrado entre el trabajador con una empresa aseguradora y compradas por el IMSS de tal manera que este Instituto calculará el monto constitutivo costo o prima necesario para su contratación y a este costo se le restará el saldo acumulado en la Afore cuenta individual del trabajador y la diferencia positiva será la suma asegurada, es decir, la cantidad que el IMSS pagará a la empresa aseguradora para la contratación de la renta vitalicia y el seguro de sobrevivencia pensión para los beneficiarios en caso de muerte del asegurado. Si por el contrario cotizaste a partir del 1 de julio de 1997 no habrá elección de que la pensión sea pagada por el Instituto (IMSS, 2013).

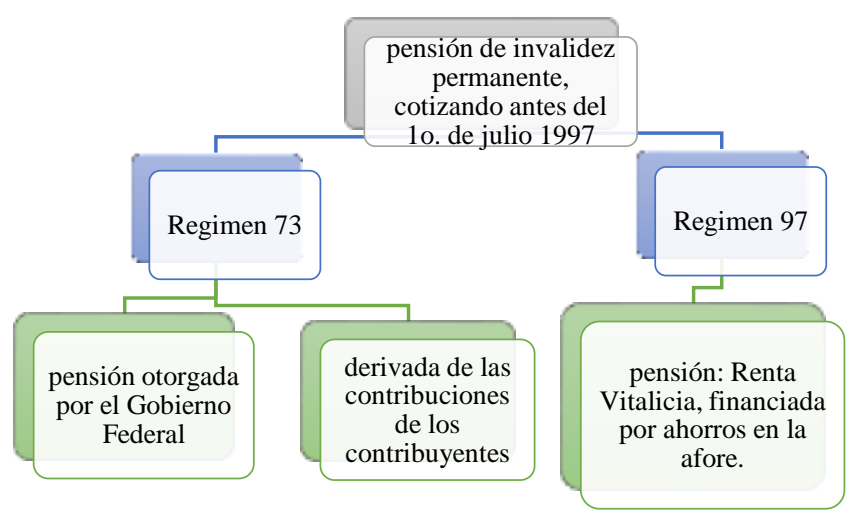

Figura 2 Forma de financiamiento. 


\section{Forma de pago y limite a las pensiones por muerte}

La pensión en el seguro de invalidez y vida conforme a los artículos 174 y 175 de la LSS del régimen 73 se calcula al igual que en el seguro de Retiro, cesantía en edad avanzada y vejez, tomando en cuenta el salario diario promedio de las últimas 250 semanas cotizadas y con base a una cuantía básica e incremento anual; aunque el procedimiento no es objeto en sí del tema en cuestión. Y la pensión en el seguro de invalidez y vida conforme a la LSS régimen 97 se cubre con lo que se tenga en la cuenta individual y si este no es suficiente, el trabajador alcanzará la denominada pensión mínima garantizada, para ello el artículo 141 prevé en su párrafo segundo y tercero respectivamente, lo siguiente:

En el caso de que la cuantía de la pensión sea inferior a la pensión garantizada, el Estado aportará la diferencia a fin de que el trabajador pueda adquirir una pensión vitalicia.

En ningún caso la pensión de invalidez, incluyendo las asignaciones familiares y ayudas asistenciales, podrá ser inferior a la pensión garantizada. (p.44)

Lo que significa que el Instituto garantiza una pensión mensual al asegurado como mínimo, equivalente a un Salario Mínimo General vigente. Actualmente dicha pensión corresponde conforme al salario mínimo en la zona centro de $\$ 102.68$ a una pensión mensual cuyo monto es de $\$ 3,080.40$ mismo que se encuentra vigente a partir del $1^{\circ}$. De enero del 2019 y en la Frontera Norte a $\$ 176.72$ a una pensión de $\$ 5,301.60$. Por lo que, debido a la precariedad en el empleo respecto al pago de salarios, el beneficio con el sistema de pensiones de 1997 no se conoce pues dependerá de los rendimientos que tenga la afore, así pues, difícilmente el trabajador podrá obtener una pensión suficiente para sobrevivir, en todo caso, solo accederá a la pensión garantizada (Ruíz et. al 2010).

Ahora bien, en ambos regímenes 73 o 97 existen otras prestaciones en dinero y que se suman a la pensión de invalidez, hablamos pues, de las asignaciones familiares y ayudas asistenciales. Las primeras son derivadas de la carga familiar para el pensionado por invalidez al existir dependencia económica para con sus beneficiarios, otorgándoles $15 \%$ para la cónyuge o concubina (o); $10 \%$ a los descendientes y $10 \%$ a cada uno de los ascendientes; a falta de esposa (o) e hijos. Por otra parte, las ayudas asistenciales se otorgan al pensionado por invalidez o a la viuda (o) cuando por su estado físico requieren ineludiblemente de la asistencia de otra persona, concediendo hasta el $20 \%$ de la pensión existiendo en los casos de la ayuda asistencial dos excepciones: la primera del $10 \%$ cuando el pensionado solo tuviere un ascendiente dependiente económico con derecho a asignación familiar de otro $10 \%$ y la segunda ayuda asistencial del $15 \%$ de la pensión cuando el pensionado no tuviera ni esposa o concubina, ni hijos ni ascendientes que dependan económicamente. Sin embargo, la cuantía básica en las pensiones de invalidez y muerte es tan solo del 35\% a diferencia del $70 \%$ que sirve de base a la cuantía en el riesgo de trabajo; si le sumamos el inconcebible límite a las pensiones que reducen en gran medida las pensiones de los beneficiarios por muerte no profesional; las asignaciones familiares cuyos porcentajes vemos que son igualmente raquíticos; las ayudas asistenciales cuya ley en comento propone "hasta" un $20 \%$, porcentaje que el mismo Instituto Mexicano del Seguro Social decretará y lo que es peor, es muy común que el asegurado desconozca la existencia de dicha prestación y el Instituto poco lo difunde aun cuando la ayuda asistencial se otorga como su nombre lo indica en los casos de requerir el asegurado o bien la viuda o viudo de la obligatoria asistencia o ayuda de otra persona, esto debido a que no pueden valerse por sí mismos. Todo esto, resulta ser contrario a las disposiciones que pretenden proteger a los asegurados frente a la pérdida de sus medios de subsistencia, por circunstancias ajenas a su voluntad, no obstante, que el asegurado ha sido participe para el financiamiento del seguro de Invalidez y Vida y de las prestaciones que se derivan del mismo con el pago de sus cuotas que, no solo le dan derecho al asegurado sino a otros derechohabientes.

Por ello recalco que, la finalidad de la seguridad social respecto a la pensión de invalidez no solo consiste en otorgar más prestaciones económicas al asegurado ahora pensionado por un riesgo no profesional, sino de proteger los medios de subsistencia a razón de que derivado de dicha incapacidad no podrá realizar el trabajo que venía desempeñando, ni obtener los ingresos suficientes para mantenerse económicamente él y su familia hasta en tanto no recupere su salud y su capacidad laboral, que le permita atender sus actividades para asegurar que se cubran sus necesidades vitales, por lo que, durante todo ese tiempo que persista su estado de invalidez el Estado de manera subsidiaria, a través del Instituto Mexicano del Seguro Social, le deberá proveer al pensionado, no solo de asistencia médica, de un subsidio o de una pensión económica que le permita una vida digna, sino que, además de reconocer el estado de invalidez, y determinar el grado de incapacidad correcto, es su obligación restablecer su nivel de salud y su incorporación al trabajo (Castillo, 2011).

Finalmente, en relación a las pensiones en el ramo de vida, cuyo riesgo protegido es la muerte no profesional de un asegurado, los beneficiarios requerirán de 150 
semanas cotizadas, no así cuando el pensionado fallecido ya contaba con una pensión de invalidez, asimismo requerirá de la contratación de la renta vitalicia y del seguro de sobrevivencia hablando de la LSS de 1997. Reiterando que la cuantía del 35\% que sirve de base para el cálculo de las pensiones de invalidez, también lo será para las pensiones que deriven de la muerte, del asegurado como del pensionado, esto en ambos regímenes, es decir, a pesar de que si se tiene la opción de pensionarse por la ley 73 en donde existe la posibilidad de adquirir una mejor pensión a diferencia de la que le pudiera corresponder con el régimen 97 que dependerá del ahorro acumulado, el cálculo de las pensiones por muerte tendrá como limite la base del 35\%. Es aquí donde las precariedades a las pensiones por muerte no profesional surgen luego de que en un principio otorga un $90 \%$ a la viuda, 20 o $30 \%$ a cada uno de los huérfanos y $20 \%$ para el caso de los ascendientes, aunque posteriormente téngase que recurrir al reajuste de pensiones y desde mi punto de vista limita la obtención a garantizar los medios de subsistencia que conllevan al pago de una pensión digna, por el contrario, en su artículo 144 la LSS establece el límite a las pensiones por viudez, orfandad y ascendencia, el cual citó a continuación para mayor entendimiento:

El total de las pensiones atribuidas a la viuda, o a la concubina y a los huérfanos de un asegurado fallecido no deberá exceder del monto de la pensión de invalidez que disfrutaba el asegurado o de la que le hubiera correspondido en el caso de invalidez. Si ese total excediera, se reducirán proporcionalmente cada una de las pensiones. Cuando se extinga el derecho de alguno de los pensionados se hará una nueva distribución de las pensiones que queden vigentes, entre los restantes, sin que se rebasen las cuotas parciales ni el monto total de dichas pensiones. (p.44)

Concretemos la idea con un ejemplo:

Pensemos que un trabajador afiliado al IMSS, en el estado de Hidalgo, sufre una enfermedad no profesional que le ocasiona una invalidez, cuenta con su esposa y 3 hijos de 9,13 y 18 años todos dependientes económicos y estudiantes en planteles del sistema educativo nacional. El salario diario promedio de las últimas 500 semanas cotizadas de dicho trabajador asciende a $\$ 360.00$ *

$360 \times 35 \%=126$ pensión diaria x $30=3,780.00$ Monto de la pensión por invalidez y límite en el caso de pensiones por muerte no profesional.

Prestaciones en dinero:
Pensión de invalidez $\$ 3,780.00$

Aguinaldo anual de 30 días de la pensión $\$ 3,780.00$

Asignaciones Familiares: (por concepto de carga familiar para el ahora pensionado por invalidez).

Cónyuge $15 \%$ de la pensión. \$567.00

3 hijos (10\% de la pensión a cada uno) 378x 3=1,134

Total, a pagar al mes: $\$ 5,481.00$

* salario por encima del SMG en la Zona centro.

Continuando con el ejemplo anterior, como consecuencia de la pensión de invalidez deviene la muerte, por tal motivo sobrevienen las pensiones por viudez y orfandad y solo a falta de los anteriores para los ascendientes. Quedando de la siguiente manera:

Imaginemos ahora que el pensionado por invalidez fallece 3 años después a consecuencia de la enfermedad que padecía. Le sobreviven su esposa y sus 3 hijos ahora de 12,16 y 21 años de edad, aun estudiantes de planteles del sistema educativo nacional.

$360 \times 35 \%=126 \times 30=3,780.00$ Monto de la pensión por invalidez y límite en el caso de pensiones por muerte no profesional.

Pensión por viudez del $90 \%$ de la pensión de invalidez $\$ 3402.00$

Aguinaldo anual para la viuda de 30 días de la pensión. $\$ 3402.00$

3 pensiones por orfandad del $20 \%$ a cada uno. Total, de pensiones $\$ 2,268$

Persisten las tres asignaciones familiares solo para los hijos, por un total de $\$ 1,134.00$

Total, mensual incluyendo las asignaciones familiares arrojaría la cantidad de $\$ 6,804.00$

Cantidad que debería de recibir la familia del pensionado por invalidez luego de su fallecimiento conforme a las cuantías básicas de viudez, orfandad, asignaciones familiares y ayudas asistenciales, esto sí, no existiera el límite a la pensión por muerte. Cabe mencionar, que aun concediendo esta cantidad mensual resulta insuficiente para que una familia mexicana conformada por 4 integrantes adquiera una digna subsistencia. Por consiguiente, de acuerdo a la LSS la suma de pensiones sin tomar en cuenta las asignaciones familiares o las ayudas asistenciales no deberán exceder del monto de la pensión de invalidez que disfrutaba el asegurado o de la que le hubiere correspondido en el caso de invalidez. Por lo que se procede al reajuste de las pensiones:

Pensión por viudez del $90 \%$ de la correspondida por concepto de invalidez, de $\$ 2,929.50$

Aguinaldo anual para la viuda de 30 días de la pensión. $\$ 2,929.50$

3 pensiones por orfandad del $20 \%$ a cada uno. Total, de pensiones $\$ 850.50$ 
Persisten las asignaciones familiares para los hijos hasta la edad de 16 años o 25 años si estudian, debido a que éstas no cesan con la muerte de la persona que las origino, es decir, del pensionado. Por la cantidad en este caso de $\$ 1,134.00$

Pensión mensual a pagar debido al límite de las pensiones por muerte en este seguro de Invalidez y vida, la cantidad de $\$ 3,780.00+1134.00$ de las asignaciones familiares. Nos arroja un total de $\$ 4.914 .00$

En este caso en particular, existió una diferencia de $\$ 1890.00$, es decir, de una pensión mensual y en total para esta familia cuyo monto resultaba ser de $\$ 6,804.00$ sin el tope a la pensión, se disminuye a una pensión de $\$ 4914.00$ al darse el fallecimiento del pensionado por invalidez, a pesar de que, la pensión mensual en vida el asegurado pensionado era de $\$ 5,481.00$ incluidas ya las prestaciones económicas por carga familiar.

Específicamente para este ejercicio es evidente que la cantidad de $\$ 4.914 .00$ por concepto de pensiones y prestaciones resulta para los beneficiarios insuficiente para satisfacer las necesidades vitales como alimento, vestido, vivienda, educación, servicios, recreación, cultura, entre otros conceptos.

\section{Conclusiones}

El límite a la pensión derivada de accidentes o enfermedades no laborales para los beneficiarios de un pensionado por invalidez o la muerte de un asegurado conforme al seguro de invalidez y vida, contradice y vulnera la finalidad de la seguridad social que consiste en garantizar la salud, una pensión y la protección de los medios de subsistencia, lo que implica que la pensión reajustada o límite a las pensiones por muerte no profesional y de manera involuntaria no corresponda a satisfacer los Derechos, Económicos, Sociales y Culturales (DESC) ligados e indispensables a la dignidad de los seres humanos y a su propio desarrollo. "Los derechos económicos, sociales y culturales se refieren a aspectos fundamentales en la vida de las personas, que tienen que ver con el desarrollo de condiciones básicas de la dignidad humana como la posibilidad de tener un nivel de vida adecuado" (Suárez, 2009 p.62). De tal forma, que al limitar la suma de pensiones por viudez, orfandad o ascendencia resulta ser de notoria precariedad en el sustento familiar, aun cuando el asegurado en vida se solidarizó con otros derechohabientes en situaciones de riesgos y compartió la carga económica con su contribución tripartita para el financiamiento de las prestaciones en dinero y en especie durante su vida laboral activa. Asimismo, los mexicanos hemos contribuido con nuestros ahorros acumulados en las cuentas individuales con el $15.1 \%$ del Producto Interno
Bruto del país; las afores han obtenido ganancias millonarias de hasta 32 mil millones de pesos por concepto de comisiones derivados de la más alta comisión equivalente a $0.98 \%$, por tanto, atendiendo a que los DESC deben satisfacerse dependiendo de los recursos y la buena organización del Estado, es justificable que se brinde a los pensionados y beneficiarios de una justicia económica reflejada en pensiones que permitan realmente atender las necesidades vitales de una familia y al mismo tiempo, que dichas pensiones se vayan ampliando de manera progresiva y no de forma limitativa. Al respecto, finalizó con lo establecido en el Convenio 102 de la Organización Internacional del Trabajo (OIT, 1955) sobre seguridad social, ratificado por México, que establece en su artículo 66 lo siguiente: "Los montos de los pagos periódicos... atribuidos para la invalidez y para la muerte del sostén de la familia serán revisados, como consecuencia del nivel de ganancias que resulten de variaciones, también sensibles, del costo de la vida" (párr.8).

\section{Referencias}

[1] Ameth, E. (5 de enero de 2015). Forbes México. Obtenido de Ten cuidado con las afores: https://www.forbes.com.mx/ten-cuidadcon-las-afores/

[2] Amezcua, O. (2002) Nueva ley del seguro social (10a. Ed) México: Gasca sicco.

[3] Castillo Cadena, F. C. (2011). La Declaratoria de Invalidez como requisito de acceso a la pensión en el sistema general de pensiones. Vniversitas, (122) 77-115

[4] CONSAR (2019). El Sistema de Pensiones de Cuentas Individuales a 22 años de su creación. Recuperado de https://www.gob.mx/consar/articulos/el-sistema-de-pensionesde-cuentas-individuales-a-22-anos-de-su-creacion207127? idiom $=$ es

[5] Constitución Política de los Estados Unidos Mexicanos. (5 de febrero de 1917). Diario Oficial de la Federación. México.

[6] García Guzmán, B. (2013) Precariedad laboral y desempleo en México, Instituto de Investigaciones jurídicas de la UNAM, 157-177, recuperado de PDF: file:///E:/garcia\%20guzman\%20brigida.pdf

[7] García Guzmán, M. (2014). Derecho a la Seguridad social. Estudios Politicos, 9 (32),83-113.

[8] González Munguí, P., Molina Gerardo \& Salazar Sosa, O. (2009) Aspectos Fundamentales de los DESC. En M del P. S. Sebastián en Derechos Económicos, Sociales y Culturales (págs. 5-501) Bogotá, Colombia: Editorial Kimpres Ltda.

[9] González Munguí, P., Molina Gerardo \& Salazar Sosa, O. (2009) Obligaciones de los Estados frente a los derechos económicos, sociales y culturales desde las normas internacionales de derechos humanos. En S.V. Quinceno en Derechos Económicos, Sociales y Culturales (págs. 5-501) Bogotá, Colombia: Editorial Kimpres Ltda.

[10] IMSS (2014) Seguro de Invalidez y Vida. Recuperado de PDF: http://www.imss.gob.mx/sites/all/statics/pdf/informes/2013201 4/08_Cap04.pdf

[11] INEGI (2019) Trabajadores asegurados en el Instituto Mexicano del Seguro Social según delegación: Recuperado de https://www.inegi.org.mx/app/tabulados/default.html?nc=833 
[12] Ley del Seguro Social. Diario Oficial de la Federación. México, 21 de diciembre de 1995.

[13] México reporta las comisiones más altas, [Fotografía] (2019), Recuperada el 19 de julio de 2019 desde: https://www.gob.mx/cms/uploads/attachment/file/474634/BP20-2019_COMISIONES_DE_LAS_AFORE_VF.pdf

[14] Naciones Unidas. (10 de diciembre de 1948). Declaración Universal de Derechos Humanos. Recuperado de : https://www.un.org/es/universal-declaration-human-rights/

[15] OIT. (27 de abril, 1955) Convenio sobre la Seguridad Social núm 102 Recuperado https://www.ilo.org/dyn/normlex/en/f?p=NORMLEXPUB:121 00:0::NO::P12100_INSTRUMENT_ID,P12100_LANG_COD E:312247,es

[15] Red DESC . Una Introducción a los derechos económicos, sociales y culturales. (s.f.). Recuperado el 29 de junio de 2019, de https://www.escr-net.org/es/derecho.

[16] Ruiz, M. M, Barboa, Q. M, \& Cuadras, B, D. (2016) Las pensiones de cesantía -vejez e invalidez de la ley del IMSS un análisis teórico práctico en trabajadores de las pymes. Ra Ximhai, 12 (4), 71-91

[17] SHCP- CONSAR (9 de julio, 2019). Las comisiones que cobra la afore [Comunicado de prensa]. Recuperado de https://www.gob.mx/cms/uploads/attachment/file/474634/BP20-2019_COMISIONES_DE_LAS_AFORE_VF.pdf

[18] Sin embargo, (2019) Recuperado de https://www.sinembargo.mx/16$07-2019 / 3613757$ 